\title{
Sensitivity analysis of the design portal frames of steel industrial buildings
}

\author{
Trong Ha Nguyen ${ }^{1, *}$ and Xuan Hung Dang ${ }^{2}$ \\ ${ }^{1}$ Faculty of Civil Engineering, Vinh University, 182 LeDuan Vinh City, Vietnam \\ ${ }^{2}$ National University of Civil Engineering, 55 GiaiPhong, HaNoi City, Vietnam
}

\begin{abstract}
This study presents aims at investigate and apply the sensitivity and reliability analysis methods to assess the reliability of a structural design according to the Vietnam standards design TCVN 5575:2012. Specifically, the sensitivity and reliability analysis of horizontal steel frame in one-story industrial building with crane is considered. The random factors that may occur during the design, fabrication, erection, and utilization stages are taken into account as much as possible. Then, the problem of number of results is analysed in order to obtain the reasonable design solution.
\end{abstract}

\section{Introduction}

Local sensitivity analysis aims at calculate the partial derivatives of the target function with respect to each variable. The simplest method is One At a Time (OAT), which was presented in numerous literatures $[1,11,15]$. A popular method using this kind of sensitivity index is that of Morris [12], which was applied in [8, 15].

Global sensitivity consists of individual sensitivity of each variable and its interaction with other variables. Sobol's sensitivity index was proposed and then widely applied [4, 9, $14,16,17]$.

The steel structure often presents high durability and includes slender components. Therefore, sensitivity and reliability analysis for steel structures was interested by many researchers $[2,3,4,6,7,13,18]$.

In this research, the author presented the global sensitivity of the input design parameters on the output parameters of the random model for horizontal steel frame, including parameters in the design, fabrication and exploitation stages. From the results of this quantitative analysis, the research assessed the overall contribution of each input parameter to the output parameters and eliminated the randomness of some parameters that exhibited small global sensitivity to all the output parameters.

\section{Sensitivity analysis}

\subsection{Sensitivity definition}

\footnotetext{
*Corresponding author: trongha@vinhuni.edu.vn
} 
Sensitivity presents the influence of an input design parameters (variables) $\boldsymbol{X}=\left(X_{1}, X_{2}, \ldots, X_{m}\right)$ on the output model $\boldsymbol{Y}=f(\boldsymbol{X})$, where, $\boldsymbol{X}=\left(X_{1}, X_{2}, \ldots, X_{m}\right)$ is the vector of design parameters in space $\mathrm{R}^{m}$ and $\boldsymbol{Y}=\left(Y_{1}, Y_{2}, \ldots, Y_{n}\right)$ is the vector of output value in space $\mathrm{R}^{n}$.

\subsection{Global Sensitivity analysis}

Considering an integrals function $\boldsymbol{Y}=f(\boldsymbol{X})$, which can be decomposed into elementary functions, as follows [11]:

$$
\begin{array}{r}
f(\boldsymbol{X})=f_{0}+\sum_{i} f_{i}\left(X_{i}\right)+\sum_{i<j} f_{i j}\left(X_{i}, X_{j}\right)+ \\
\cdots+f_{1 \cdots m}\left(X_{1}, \ldots, X_{m}\right)
\end{array}
$$

where $X_{\mathrm{i}}$ is the input random variables and independent probability. The variance of the output variable can be expressed as $[11,15$, and 16]:

$$
\operatorname{Var}[Y]=\sum_{i=1}^{m} V_{i}+\sum_{1 \leq i<j \leq m}^{m} V_{i j}+\ldots+V_{1 \ldots m}
$$

where

$$
\begin{gathered}
V_{i}=\operatorname{Var}\left[E\left[Y \mid X_{i}\right]\right] ; V_{i j}=\operatorname{Var}\left[E|Y| X_{i} X_{j}\right]-V_{i}-V_{j} \\
V_{1 \ldots n}=\operatorname{Var}[Y]-\sum_{i=1}^{m} V_{i}-\sum_{1 \leq i<j \leq m}^{m} V_{i j}-\sum_{1 \leq i_{1}<\ldots<i_{n-1} \leq m}^{m} V_{i_{1} \ldots i_{m-1}}
\end{gathered}
$$

A first order Sobol' index is determined by:

$$
S_{i}=\frac{V_{i}}{\operatorname{Var}[Y]}
$$

A second order Sobol' index is determined by:

$$
S_{i j}=\frac{V_{i j}}{\operatorname{Var}[Y]}
$$

Total order Sobol' index is then determined by:

$$
S_{T i}=S_{i}+S_{i j}+S_{i k l}+\ldots+S_{i \ldots n}
$$

The Sobol indices are often estimated using Monte Carlo method and the computation program is written using Python language and is validated by comparing its results with Ishigami funtions.

\section{Construction of stochastic model of the design problem of horizontal steel frames in industrial buildings}

\subsection{Deterministic design problem of horizontal frame}


The procedure for the deterministic design problem of horizontal frame in industrial building is detailed in the literature [19], which consists of the following steps according to TCVN 5575:2012.

Analyze the frame to determine the internal forces at 6 sections ( 4 column sections and 2 beam sections) and determine the horizontal displacement at the top of column $\Delta_{c}^{i}(i=1 . .3$ ). Take the basic combination of internal forces according to the standard and record the combinations corresponding to $M_{\max }^{+}, N_{t u} ; M_{\max }^{-}, N_{t u} ; N_{\max }, M_{t u}$ on each section. Calculate the parameters $\left(\sigma_{b c}^{i j}, \sigma_{o d c}^{i j}, n_{b c}^{i j}, n_{c c}^{i j}\right)$ and $\left(\sigma_{b d}^{i k}, \sigma_{o d d}^{i k}, n_{b d}^{i k}, n_{c d}^{i k}\right)$, where $i=1 . .3$ denotes 3 combinations of internal forces recorded at each section; $j=1 . .4$ denotes 4 column sections and $k=1 . .2$ denotes 2 beam sections.

Output parameters for column sections:

$$
\begin{aligned}
\left(\sigma_{b c}^{j}, \sigma_{o d c}^{j}\right) & =\max _{i=1 . .3}\left(\sigma_{b c}^{i j}, \sigma_{o d c}^{i j}\right) \\
\left(n_{b c}^{j}, n_{c c}^{j}\right) & =\min _{i=1 . .3}\left(n_{b c}^{i j}, n_{c c}^{i j}\right)
\end{aligned}
$$

Output parameters for beam sections:

$$
\begin{aligned}
\left(\sigma_{b c}^{k}, \sigma_{o d c}^{k}\right) & =\max _{i=1.3}\left(\sigma_{b c}^{i k}, \sigma_{o d c}^{i k}\right) \\
\left(n_{b c}^{k}, n_{c c}^{k}\right) & =\min _{i=1 . .3}\left(n_{b c}^{i k}, n_{c c}^{i k}\right)
\end{aligned}
$$

Output parameters for displacements at the top of columns:

$$
\Delta_{c}=\max _{i=1.3}\left(\Delta_{c}^{i}\right)
$$

Fig.1. presents the proposed The Steel Frame Design (SFD) program, which is written by the author using the Python programming language. 


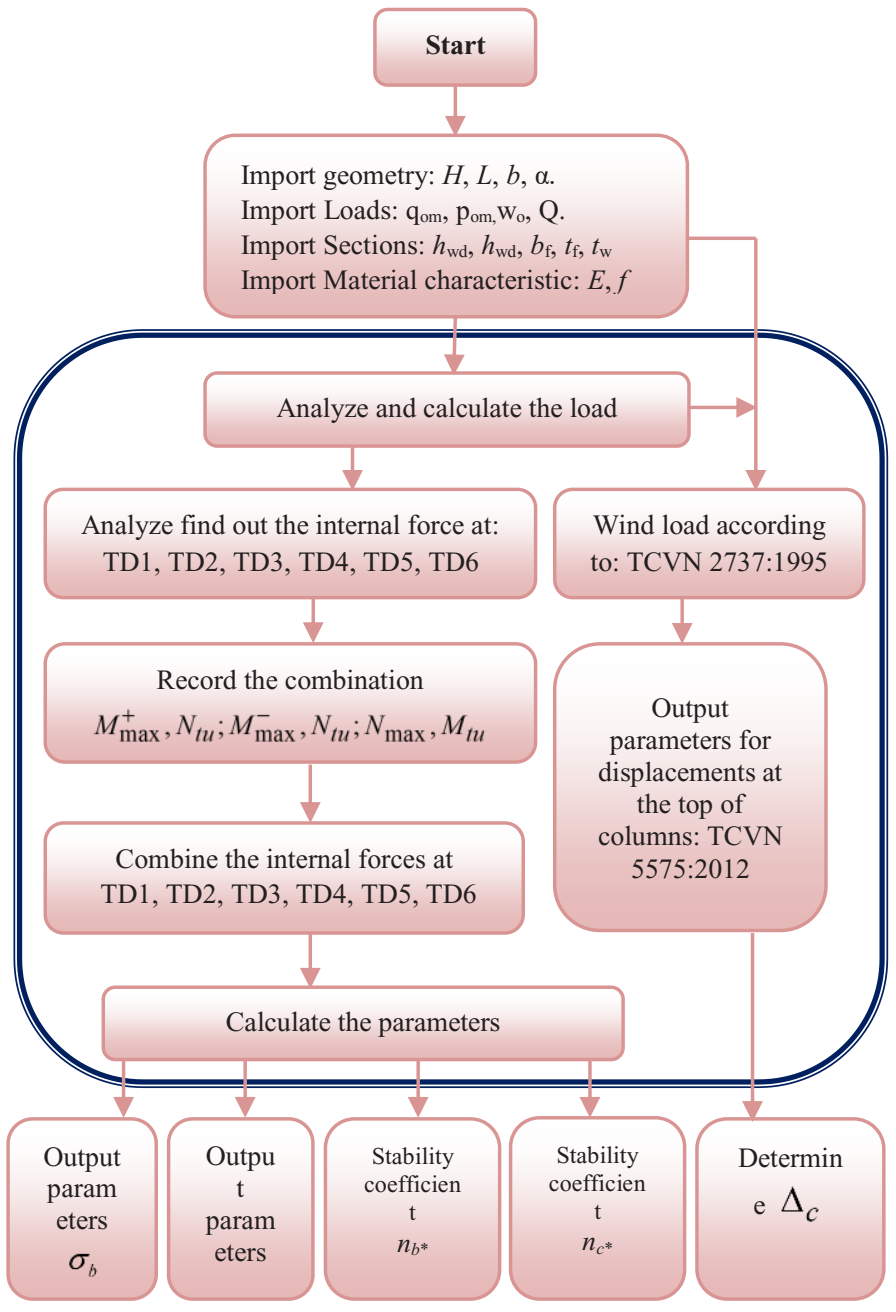

Fig. 1. The flow chart for the SFD program.

\subsection{Stochastic model for the design problem of steel frame}

Fig.2. Presents the flow chart of the stochastic model for design problem of horizontal frame in industrial building, which is constructed based on the SFD model when the input design parameters are randomized. 


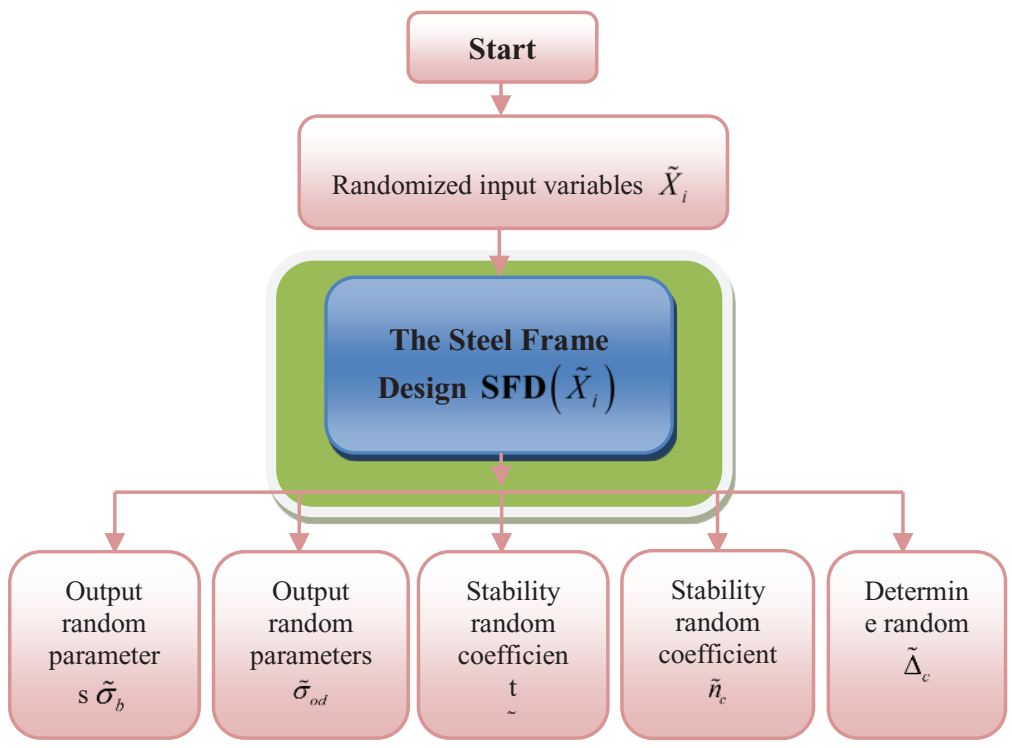

Fig. 2. Stochastic model for design problem of steel frame.

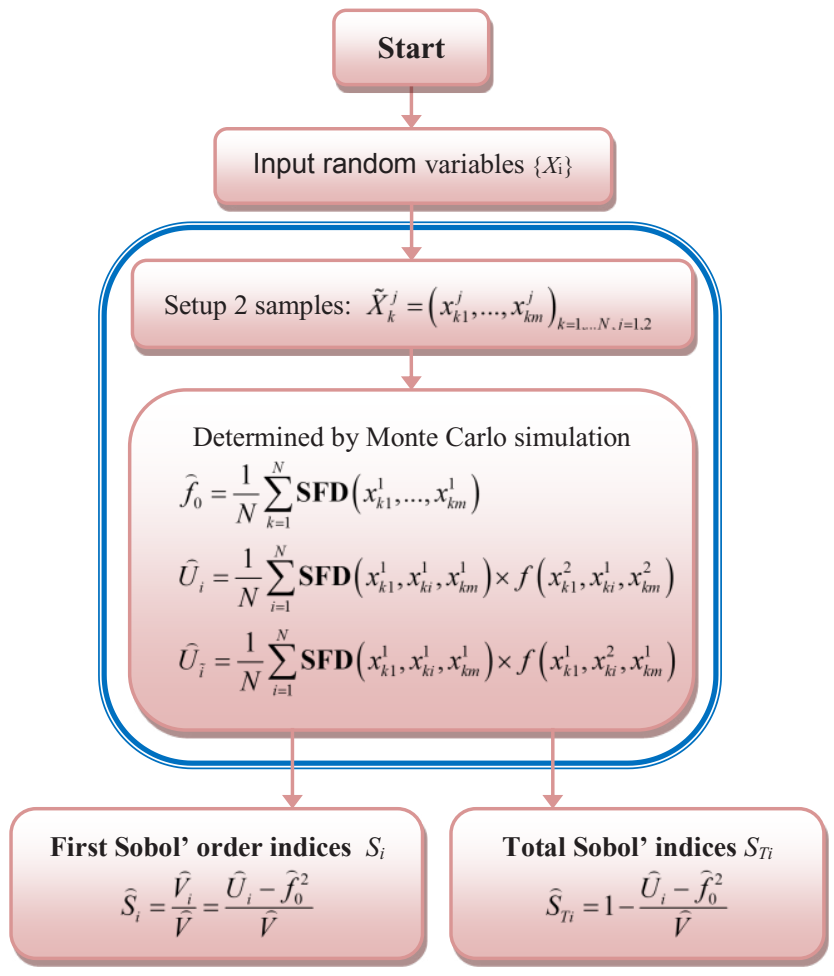

Fig. 3. The algorithm for global sensitivity analysis of steel frame. 


\subsection{Sensitivity analysis program}

The sensitivity analysis program for design of steel frame is proposed based on the algorithm of the global sensitivity analysis program using the Sobol Sensitivity Index (GSAP) and stochastic model of steel frame design problem, as illustrated in Fig. 3.

\section{Sensitivity and reliability analysis of the design problem of horizontal steel frame in industrial buildings}

In this sections, the program developed in sections 3 will be used to assess the sensitivity and reliability of a design of steel frame which is designed according to the standard TCVN 5575:2012 and solve the economic-technical problem associated with reliability.

\subsection{Sensitivity analysis of design parameters of steel frame}

The global sensitivity of the input parameters on each of output parameters $\left(\sigma_{b c}, \sigma_{o d c}, n_{b c}, n_{c c}, \sigma_{b d}, \sigma_{o d d}, \Delta_{c}, n_{b d}, n_{c d}\right)$ of the steel frame will be analyzed.

Table 2. Input values of random variables.

\begin{tabular}{|c|c|c|c|c|c|}
\hline & $X_{i}$ & Rules & $\begin{array}{l}\text { Definite } \\
\text { value }\end{array}$ & Interval variable & Units \\
\hline 1. & $q_{0 m}$ & Normal & 0,31 & {$[0,279 ; 0,341]$} & $\mathrm{kN} / \mathrm{m}^{2}$ \\
\hline 2. & $p_{0 m}$ & Normal & 0,30 & {$[0,270 ; 0,330]$} & $\mathrm{kN} / \mathrm{m}^{2}$ \\
\hline 3. & $Q$ & Normal & 10,00 & {$[9,00 ; 11,000]$} & Tấn \\
\hline 4. & $w_{0}$ & Normal & 0,95 & {$[0,855 ; 1,045]$} & $\mathrm{kN} / \mathrm{m}^{2}$ \\
\hline 5. & $b_{f}$ & Normal & 0,25 & {$[0,225 ; 0,275]$} & $\mathrm{m}$ \\
\hline 6. & $t_{f}$ & Normal & 0,015 & {$[0,0135 ; 0,0165]$} & $\mathrm{m}$ \\
\hline 7. & $t_{w}$ & Normal & 0,008 & {$[0,0072 ; 0,0088]$} & $\mathrm{m}$ \\
\hline 8. & $h_{w c}$ & Normal & 0,38 & {$[0,342 ; 0,418]$} & $\mathrm{m}$ \\
\hline 9. & $h_{w d}$ & Normal & 0,38 & {$[0,342 ; 0,418]$} & $\mathrm{m}$ \\
\hline 10. & $E$ & Normal & $2,1 \mathrm{E} 8$ & {$[1,89 \mathrm{E} 8 ; 2,31 \mathrm{E} 8]$} & $\mathrm{kN} / \mathrm{m}^{2}$ \\
\hline 11. & $f$ & Normal & $2,1 \mathrm{E} 5$ & {$[1,89 \mathrm{E} 5 ; 2,31 \mathrm{E} 5]$} & $\mathrm{kN} / \mathrm{m}^{2}$ \\
\hline 12. & $L$ & Normal & 24,00 & {$[21,600 ; 26,400]$} & $\mathrm{m}$ \\
\hline 13. & $b$ & Normal & 6,30 & {$[5,670 ; 6,930]$} & $\mathrm{m}$ \\
\hline 14. & $\alpha$ & Normal & 5,71 & {$[5,139 ; 6,281]$} & digri \\
\hline 15. & $H$ & Normal & 10.00 & {$[9.000: 11.000]$} & $\mathrm{m}$ \\
\hline 16. & Fsv & Normal & 0,5 & {$[0,450 ; 0,550]$} & digri \\
\hline 17 & $\Delta \mathrm{sv}$ & Normal & 008 & {$[0072 \cdot 0088]$} & $\mathrm{m}$ \\
\hline
\end{tabular}


Input random variables are assumed to be independent probability and uniformly distributed, as detailed in Table 2 . The variations of each variable are assumed to be in the range around $\pm 10 \%$ of the deterministic values in order to show the influences of the variables.

\subsubsection{Convergence of Monte Carlo simulation}

Fig. 4. shows the convergence of the results obtained from the survey problem when the objective function is the column strength and the column displacement with the sample size of $10^{4} ; 2.10^{4} ; 3.10^{4} ; 4.10^{4} ; 4,5.10^{4} ; 5.10^{4}$, respectively.
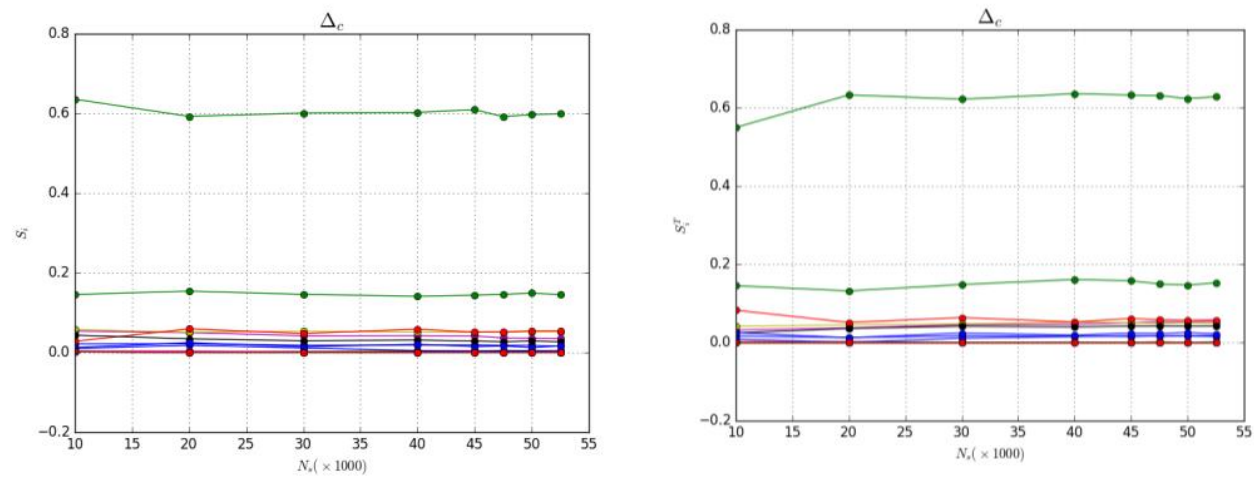

Fig. 4. The convergence of Monte Carlo simulation.

\subsubsection{Sensitivity of the input parameters on theto output parameters}

The first-order and Global total order sensitivity analysis indices results of the design parameters onto the output parameters are shown in Figs. 5-13. It is observableseen from these figures that the obtained results are consistent with the qualitative analysis results. The input paprameters, and that that present aexhibit small global sensitivity onto all the output parameters, will be assumed to be deterministic parameters in reliability analysis.
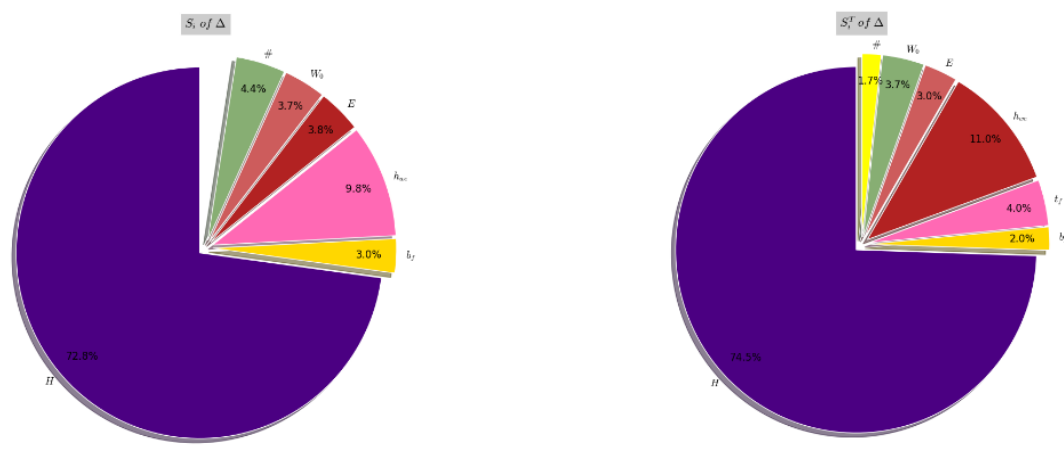

Fig. 5. First order and total order sensitivity Sobol' index of $\left(\Delta_{C}\right)$. 

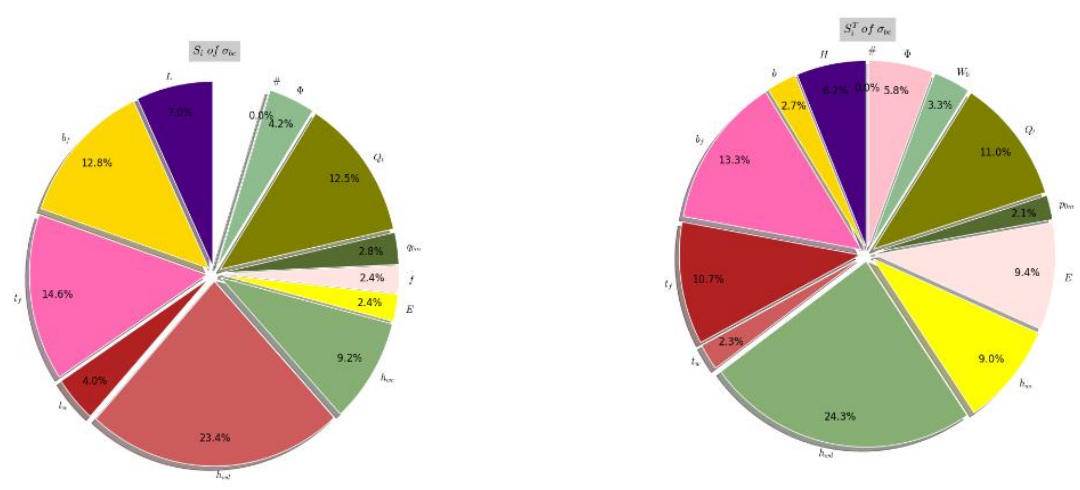

Fig. 6. First order and total order sensitivity Sobol' index of $\left(\sigma_{b c}\right)$.
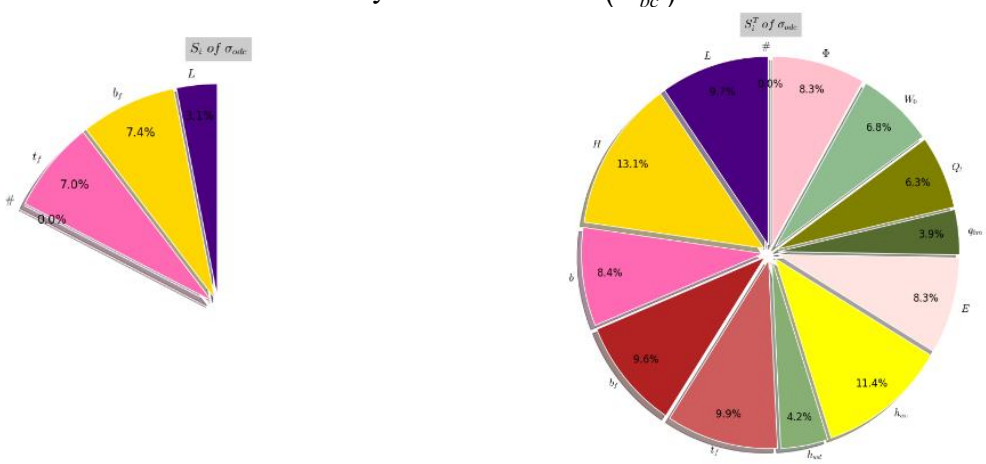

Fig. 7. First order and total order sensitivity Sobol' index of $\left(\sigma_{o d c}\right)$.
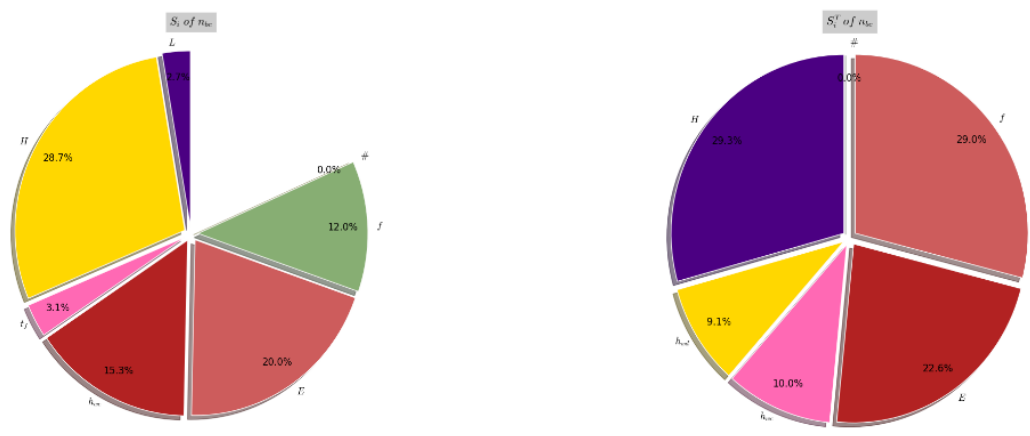

Fig. 8. First order and total order sensitivity Sobol' index of $\left(n_{b c}\right)$. 

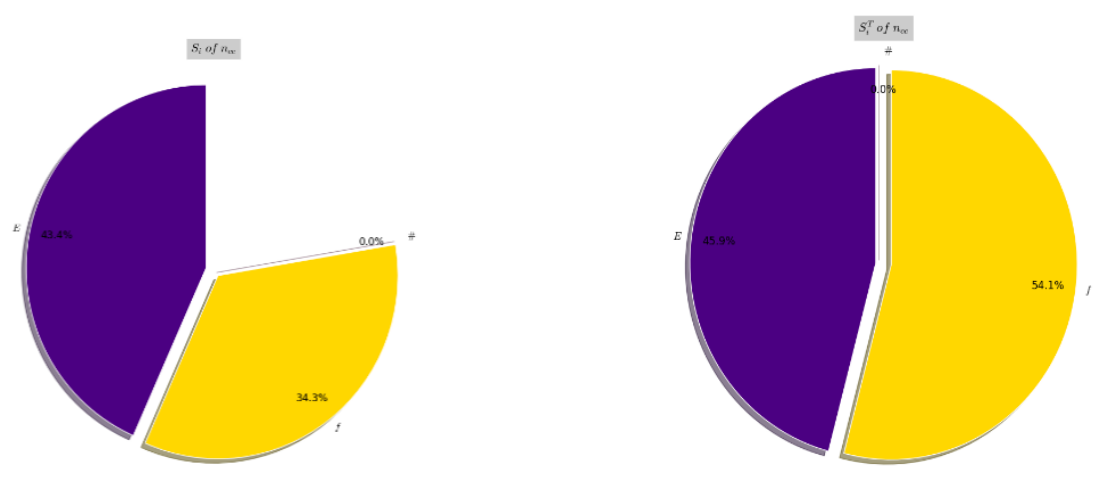

Fig. 9. First order and total order sensitivity Sobol' index of $\left(n_{c c}\right)$.
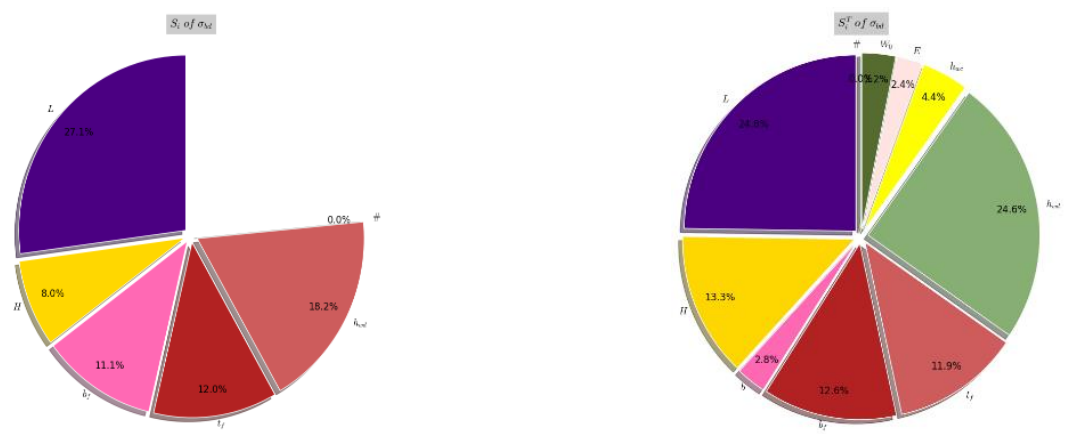

Fig. 10. First order and total order sensitivity Sobol' index of $\left(\sigma_{b d}\right)$.
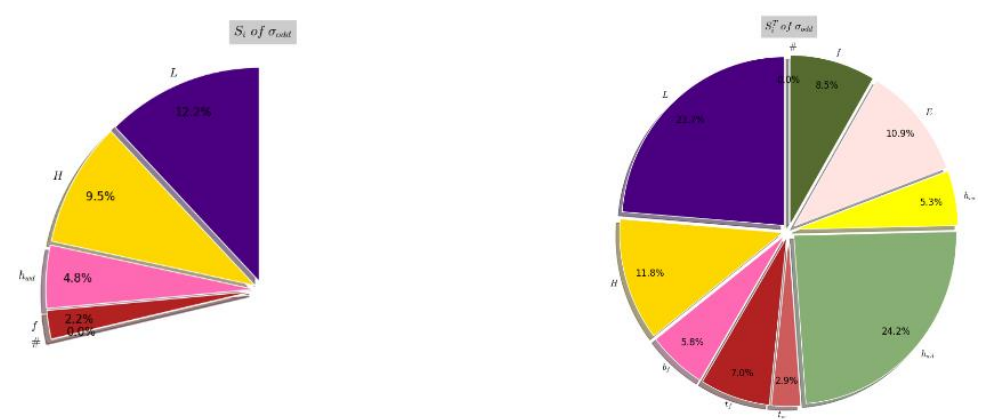

Fig. 11. First order and total order sensitivity Sobol' index of $\left(\sigma_{\text {odd }}\right)$.
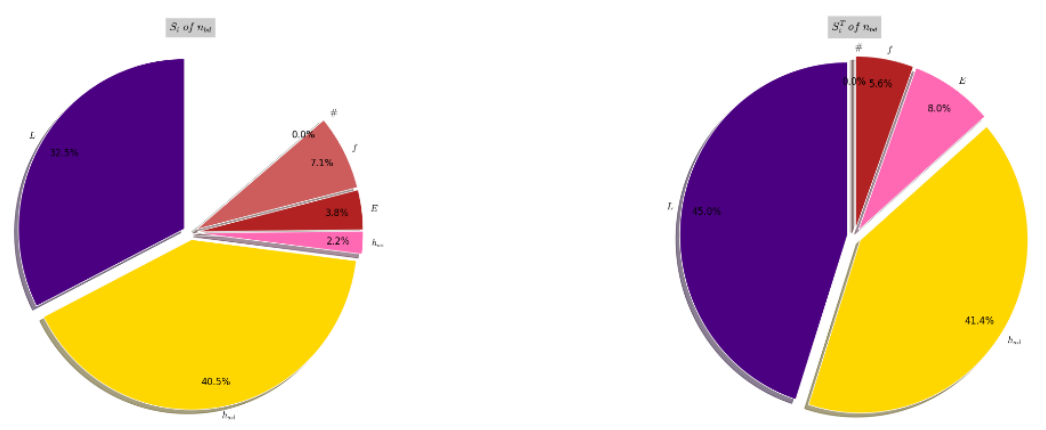
Fig. 12. First order and total order sensitivity Sobol' index of $\left(n_{b d}\right)$
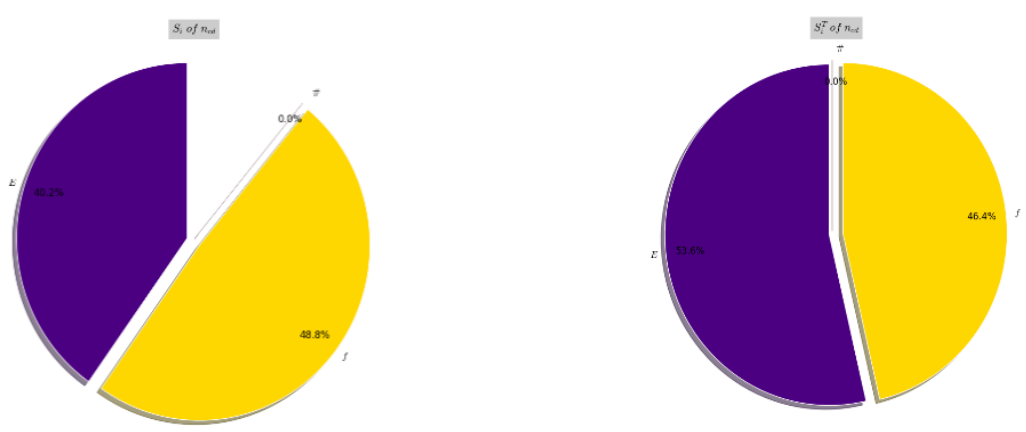

Fig. 13. First order and total order sensitivity Sobol' index of $\left(n_{c d}\right)$.

\section{Conclusion}

This research investigates the algorithm and develops a Global Sensitivity analysis program using the Sobol 'sensitivity index and Monte Carlo simulation method. The program is written using Python language and demonstrated to be accurate by comparing its results with Ishigami funtions and research investigates the algorithm and develops a reliability analysis program using Monte Carlo simulation method. The computation program is written using Python language and applied to the reliability analysis of planar frame structure using the stable condition to illustrate the method.

The research develops a process for assessing the sensitivity and reliability of building structures using the proposed sensitivity and reliability analysis programs. This process is then applied to analyze the sensitivity and reliability of a horizontal frame in single-storied industrial building with crane to illustrate the method.

\section{References}

1. V.V. Bolotin, Methods of probability and reliability theory in the calculation of structures (Moscow, 1982)

2. J.R. Benjamin, A.Cornell, Probability, Statistics and Decision for Civil Engineers (McGraw-Hill Book co., 1970)

3. G. Cederbaum, I. Elishakoff, L. Librescu, Composite Structures 15, 161-167 (1990)

4. D.G. Cacuci, Journal of Mathematical Physics 22, 2794 - 1981 (1981)

5. X.H. Dang, Identification de la variabilité spatiale des champs de contraintes dans les agrégats polycristallins et application à l'approche locale de la rupture, Thèse de Doctorat (Université Blaise Pascal, Clermont Ferrand, France, 2012)

6. A.D. Kiureghian, Engineering structures 18-6, 412-424 (1990)

7. Eurocode 3, Design of steel stluctures (1993)

8. A. Habib, Finite Elements in Analysis and Design 46, 571-584 (2010)

9. A. Hamed, Advances in Research 2(12), 950-966 (2014)

10. J. Morio, Eur. J. Phys. 32, 1577-1583 (2011)

11. M. Lemaire, Fiabilité des Structures: Couplage mescano-fiabiliste (Hermes, 2005)

12. B.K. Low, W.H. Tang, J. Engrg. Mech., 749-752 (1997) 
13. Art B. Owen, Uncertainty Quantification 1, 19-41 (2008)

14. T. Palle Christensen, J.B. Michael, Application of structural systems reliability theory springe (Verlag Berlin Heidelberg, New Yord, Tokyo, 1986)

15. W. Qi, C. Zhang, J. Chu, H. Zhou, Journal of Hydrology and Environment Research 11 (2009)

16. E.M. Robert, Corrosion Science 47, 2391-2410 (2005)

17. A. Rjanitzyne, Calcul à la Rupture et Plasticité des Constructions (Eyrolles, Paris, 1959)

18. A. Saltelli, K. Chan, E. Scott, Global Sensitivity Analysis (The Primer New York, Wiley, 2000)

19. I.M. Sobol', A Frimer for the Monte Carlo Method (Press, Inc., 2000 Corporate Blvd, Florida, 1994) 